DOI: https://doi.org/10.46296/yc.v5i9ucedespsoct.0123

\title{
PROCEDIMIENTO TECNOLÓGICO PARA LA ELABORACIÓN DE MINIQUESOS CON FINES INVESTIGATIVOS
}

\section{MINICHEESES ELABORATION TECHNOLOGICAL PROCEDURE WITH INVESTIGATIVE PURPOSES}

\author{
Salinas-Rojas Liyoesmín ${ }^{1}$; Pérez-Mayedo Thalía ${ }^{2}$; Hernández-Sariego Taimy ${ }^{3}$; \\ Ramos-López Lisandro ${ }^{4}$ \\ ${ }^{1}$ Centro de Ingeniería Genética y Biotecnología CIGB, Circunvalación Norte y Avenida \\ Finlay. Camagüey, Cuba. Correo: liyoesmin.salinas@cigb.edu.cu. ORCID ID: \\ https://orcid.org/0000-0001-5405-3237
}

${ }^{2}$ Estudiante de Licenciatura en Ciencias Alimentarias de la Universidad de Camagüey "Ignacio Agramonte Loynaz". Camagüey, Cuba. ORCID ID: https://orcid.org/00000002-6291-8787

${ }^{3}$ Departamento de Ciencia y Tecnología de los Alimentos, Universidad de Camagüey "Ignacio Agramonte Loynaz". Camagüey, Cuba. ORCID ID: https://orcid.org/00000002-9638-2765

${ }^{4}$ Departamento de Ciencia y Tecnología de los Alimentos, Universidad de Camagüey "Ignacio Agramonte Loynaz". Camagüey, Cuba. ORCID ID: https://orcid.org/00000003-2564-7671

\section{Resumen}

Las investigaciones relacionadas con la producción de quesos generalmente son muy costosas debido, entre otros factores, al elevado gasto de materia prima, por lo que en los últimos años se ha enfocado la atención al desarrollo de tecnologías para la producción de miniquesos. El objetivo del presente trabajo es desarrollar un procedimiento tecnológico para la producción de miniquesos Fresco Criollo con calidad similar a la de los quesos de producción industrial, para facilitar la realización de investigaciones. En la confección del procedimiento se analizaron los protocolos reportados en la literatura científica y la tecnología empleada en la fabricación industrial del tipo de queso seleccionado. El tiempo de centrifugación se varió en dos niveles (15 y $30 \mathrm{~min}, 30$ y $60 \mathrm{~min}$ ); se evaluaron el pH, el contenido de humedad, la grasa y GES. Los miniquesos que presentaron una calidad químico-física similar a las muestras de queso industrial fueron sometidos a una evaluación sensorial. Los mejores resultados se obtuvieron con 15 y 30 minutos de centrifugación. El procedimiento desarrollado posibilita la producción de miniquesos a escala de laboratorio con una calidad químico-física y sensorial similar a la de los quesos Frescos Criollos de fabricación industrial.

Palabras claves: miniquesos; calidad; producción de quesos; procedimiento tecnológico.

\begin{abstract}
Research related to cheese production is generally very expensive due to, among other factors, the high cost of raw materials, that is why in recent years attention has been focused on the development of technologies for the production of mini-cheeses. The objective of this work is to develop a technological procedure for the production of Fresco Criollo mini-cheeses with a quality similar to that of industrially produced cheeses, to facilitate research. In the preparation of the procedure, the protocols reported in the scientific literature and the technology used in the industrial manufacture of the selected type of cheese were analyzed. The centrifugation time was varied in two levels (15 and $30 \mathrm{~min}, 30$ and $60 \mathrm{~min}$ ); $\mathrm{pH}$, moisture content, fat and GES were
\end{abstract}

Información del manuscrito:

Fecha de recepción: 26 de julio de 2021.

Fecha de aceptación: 29 de septiembre de 2021.

Fecha de publicación: 11 de octubre de 2021. 
evaluated. The mini-cheeses that presented a chemical-physical quality similar to the industrial cheese samples were subjected to a sensory evaluation. The best results were obtained with 15 and 30 minutes of centrifugation. The procedure developed enables the production of minicheeses on a laboratory scale with a chemical-physical and sensory quality similar to that of the Frescos Criollos cheeses of industrial manufacture.

Keywords: minicheeses; quality; cheese production; technological procedure.

\section{Introducción}

Entre los derivados lácteos, el queso constituye el grupo más diverso. Su producción es una consecución de reacciones bioquímicas que pueden generar productos altamente deseables o con olores y sabores desagradables si esas reacciones se producen desbalanceadamente. Despierta el interés de los científicos (Fox, Guinee, Cogan y McSweeney, 2017), la investigación de su microbioma (Yeluri Jonnala, McSweeney, Sheehan, y Cotter, 2018), maduración (Santiago-López et al., 2018), olor (Peralta, Wolf, Perotti, Bergamini y Hynes, 2016) y conservación (Giri, Tripathi y Kotwaliwale, 2018), etc. El desarrollo de estas investigaciones usualmente requiere de la producción de quesos experimentales. El número de tratamientos y sus correspondientes réplicas hacen que estos experimentos sean costosos, laboriosos y con baja reproducibilidad (Bachmann,
Kruijswijk, Molenaar, Kleerebezem y van Hylckama, 2009).

Se han desarrollado algunos protocolos para la elaboración de miniquesos. Ante la inexistencia de tecnologías de investigación a gran escala que permitieran estudios efectivos de los cultivos queseros, se diseñó un proceso para la fabricación a gran escala de miniquesos (Cheddar y Gouda, 170 $\mathrm{mg}$ ) para investigaciones eficaces de cultivos iniciadores (Bachmann et al., 2009). Debido a que la mayoría de los modelos desarrollados previamente se empleaban en estudios microbiológicos y sensoriales, se desarrolló uno para el análisis de perfil de textura de queso Fresco y queso Chihuahua (Trancoso-Reyes, GutiérrezMéndez, Sepulveda y HernándezOchoa, 2014). El interés por el estudio de las interacciones que se producen entre microorganismos que intervienen en la maduración de los quesos produjo el desarrollo de 
un modelo para la elaboración de miniquesos a escala de laboratorio con un peso promedio de $6.2 \mathrm{~g}$ (Pham, Landaud, Lieben, Bonnarme y Monnet, 2019). Otro uso de protocolos para elaborar miniquesos ha sido en el estudio de como el contenido de $\mathrm{NaCl}$ influye en la producción de putrescina, una amina biógena (Del Rio, et al., 2016). Una nueva metodología se empleó para elaborar miniquesos con una masa de $10 \mathrm{~g}$ con la intención de evaluar condiciones ambientales y la suceptibilidad de L. monocytogenes a fagos en la búsqueda de tratamientos para controlar este patógeno que suele afectar los derivados lácteos como el queso (Henderson et al., 2019).

El empleo de las metodologías desarrolladas para producir miniquesos constituye una alternativa para reducir los costos y facilitar las investigaciones. Sin embargo, en la Universidad de Camagüey no se cuenta con una metodología adecuada a las condiciones de los laboratorios y sus investigaciones relacionadas con quesos. A partir de la situación antes mencionada la presente investigación responde al siguiente problema: ¿Qué metodología seguir para obtener miniquesos con calidad comparable a los quesos de producción industrial, acorde a las condiciones existentes en el área investigativa de la Universidad de Camagüey? Por ello el objetivo de este trabajo es desarrollar un procedimiento tecnológico para la producción de miniquesos Fresco Criollo con calidad químico-física y sensorial similar a la de los quesos de producción industrial para facilitar la realización de investigaciones.

\section{Metodología}

Los experimentos se realizaron en la Planta Piloto de la Universidad de Camagüey Ignacio Agramonte Loynaz. El diseño del proceso tecnológico para elaborar los miniquesos se desarrolló mediante el estudio de publicaciones científicas que abordaban el tema y mostraban resultados favorables. Con la finalidad de definir las etapas y parámetros de operación indispensables para cumplir con las especificaciones de calidad del queso semiduro Fresco Criollo se analizó la NEIAL-1609.27: 1954 (norma por la que se rigen en la fábrica para la producción de este 
queso). Finalmente, se analizaron las similitudes y diferencias entre las diferentes tecnologías estudiadas.

Durante la etapa de corte y agitación de la cuajada en la elaboración de los miniquesos se utilizó un dispositivo de acero inoxidable a partir de la modificación del diseñado antes por Bachmnann et al. (2009). El nuevo dispositivo (Fig. 1) se compone de dos partes: la inferior consiste en una gradilla que brinda soporte a 12 tubos de ensayo (50
$\mathrm{mL}$ ) con una separación entre sus centros de $34 \mathrm{~mm}$; la parte superior consta de una lámina que tiene fijadas 12 varillas de $98 \mathrm{~mm}$ de largo y $3 \mathrm{~mm}$ de diámetro, las que coinciden con el punto medio de los tubos de ensayo. El dispositivo permite la elaboración simultánea, pero independiente, de 12 miniquesos, el peso de los miniquesos (6 a 7 g) posibilita realizarles los análisis de calidad necesarios.

Figura 1. Dispositivo diseñado para el corte y agitación de la cuajada.

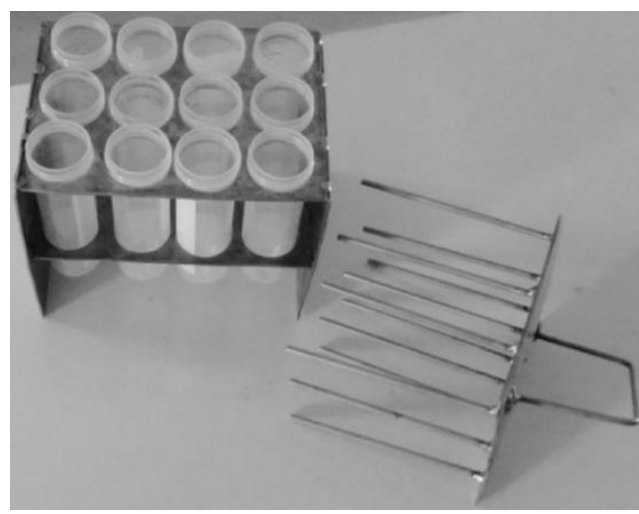

Fuente: Salinas-Rojas (2021).

Se desarrollaron 12 corridas experimentales a partir de materias primas suministradas por una industria láctea del territorio. En el estudio se varió el tiempo de centrifugación en dos niveles seleccionados (15 y 30 min en cada paso de centrifugación, respectivamente, en la primera variante y 30 y 60 min respectivamente en la segunda variante) para comprobar con cuál se alcanza las características de calidad de los quesos frescos criollos. Se evaluó su impacto sobre el $\mathrm{pH}$, los contenidos de humedad y grasa. La calidad de los miniquesos obtenidos se comparó con la de muestras de quesos Fresco Criollo 
industriales elaborados a partir de la misma materia prima.

Como parte de la evaluación de la calidad químico-física y sensorial de los miniquesos se determinaron los siguientes indicadores: humedad mediante un analizador electrónico de humedad (modelo SMO 01), valor de $\mathrm{pH}$ con el uso de un potenciómetro modelo PHS-3F, grasa mediante el método butirométrico (NC 78-18, 1984) y grasa en extracto seco (GES) se calculó a partir de la siguiente fórmula:

$$
G E S=\frac{\% G}{100-\% H} * 100
$$
G: grasa
$\mathrm{H}$ : humedad

Para el procesamiento de los resultados fueron utilizados el programa Microsoft Excel y el paquete estadístico Statgraphics Centurión versión XV como se muestra a continuación:

- Cálculo de media, desviación estándar (DS) y coeficiente de variación (CV) a los resultados de los análisis químico-físicos de los quesos.

- Análisis de varianza ANOVA y Test de Múltiples Rangos para comprobar la existencia o no de diferencias significativas entre los resultados de los análisis químico-físicos obtenidos para los dos tratamientos de centrifugación y los de las 12 muestras de queso Fresco Criollo fabricado en La Vaquita.

A los miniquesos resultantes de las combinaciones de variables y niveles que manifestaron los mejores resultados se les realizó una evaluación de sus propiedades sensoriales a través de un Procedimiento Analítico de Evaluación Sensorial (PAES) para productos de la industria láctea cubana (Instrucción S.C.C, 2006). Las determinaciones fueron realizadas por cinco catadores analíticos y los atributos evaluados fueron: aspecto, olor, sabor y textura.

\section{Resultados}

Descripción del procedimiento tecnológico para la elaboración de miniquesos Frescos Criollo.

Al analizar el proceso tecnológico para la elaboración industrial del queso Fresco Criollo y los protocolos reportados por (Bachmann et al., 2009; Trancoso-Reyes et al., 2014; 
Van Tassell et al., 2015) de manera general, se aprecian como principales diferencias en las etapas de corte y agitación de la cuajada la forma del dispositivo empleado (en los miniquesos mayormente tienen forma cilíndrica); tipo, tiempo y velocidad del movimiento realizado. Difieren también el tiempo y temperatura de cocción. Además, durante la elaboración de los miniquesos se realizan dos pasos de centrifugación: el primero para garantizar los niveles de humedad necesarios y el segundo para garantizar una adecuada textura (Bachmann et al., 2009; TrancosoReyes et al., 2014). Las valoraciones realizadas de las diferentes tecnologías desarrolladas permitieron diseñar el proceso tecnológico que se muestra en la Figura 2.

Figura 2. Procedimiento tecnológico para la elaboración de los miniquesos Fresco Criollo.

\begin{tabular}{|c|}
\hline Estandarización Grasa/Proteína (35\% mín. GES) \\
\hline Pasteurización $\left(63-65^{\circ} \mathrm{C}\right.$ por 30 minutos) \\
\hline Enfriamiento $\left(32^{\circ} \mathrm{C}\right)$ \\
\hline Vertido en tubos de ensayos \\
\hline $\begin{array}{c}\text { Adición e inoculación }\left(20 \mu \mathrm{L} \text { solución } \mathrm{CaCl}_{2}(6,6 \mathrm{M}), 1 \% \text { de }\right. \\
\text { cultivo })\end{array}$ \\
\hline Coagulación (40 minutos) \\
\hline Corte y agitación: $20 \mathrm{~min}$ ( $3 \mathrm{seg}$ de corte por $3 \mathrm{~min}$ de reposo) \\
\hline Reposo (5 minutos) \\
\hline Centrifugación $\left(1100 \mathrm{~min}^{-1}\right.$ por 15 o 30 minutos a $\left.11^{\circ} \mathrm{C}\right)$ \\
\hline Desuerado \\
\hline Centrifugación (1100 $\mathrm{min}^{-1}$ por 30 o 60 minutos) \\
\hline Desuerado \\
\hline Salado (5 minutos) \\
\hline Limpieza y secado \\
\hline Conservación $\left(2-8^{\circ} \mathrm{C}\right)$ \\
\hline
\end{tabular}

Fuente: Salinas-Rojas (2021) 
A continuación, se explican brevemente las diferentes etapas que conforman el proceso tecnológico diseñado:

- Estandarización:

Con el objetivo de optimizar los rendimientos la leche se estandariza a 2,3-2,5 \% de grasa según el contenido de proteína, para garantizar en el producto terminado un $35 \%$ mínimo de GES.

- Pasteurización:

En vistas a eliminar microorganismos o enzimas que pueden ser nocivos al proceso de elaboración del queso y bacterias patógenas que pueden afectar al consumidor (Fox et al., 2017), la leche se pasteuriza a una temperatura de $63-65^{\circ} \mathrm{C}$ durante 30 minutos con el empleo de un baño termostatado.

\section{- Enfriamiento:}

Una vez concluida la pasteurización se enfría rápidamente la leche hasta los $32 \stackrel{\circ}{\circ}$ para continuar con el proceso.

- Vertido en tubos de ensayos:
Se vierten en cada tubo de ensayo $50 \mathrm{~mL}$ de leche a $32^{\circ} \mathrm{C}$.

- Adición e inoculación:

Durante esta etapa se añaden los aditivos necesarios como el cloruro de calcio y el cultivo (opcional para este tipo de queso). Se agregan 20 $\mu \mathrm{L}$ de solución de cloruro de calcio $(6,6 \mathrm{M})$ y se inocula al $1 \%$, para luego madurar la leche durante 40 minutos en vista a aumentar la acidez para un funcionamiento adecuado del cuajo.

En el caso de que no se emplee cultivo, se deja madurar la leche hasta que el $\mathrm{pH}$ disminuya a 6,4 ; con el objetivo de garantizar que el producto final cumpla con el valor requerido para este indicador.

- Coagulación:

Persigue el objetivo de coagular las proteínas de la leche mediante la adición de cuajo, cuya cantidad a añadir va a estar en dependencia de la fortaleza del mismo. Esta etapa dura aproximadamente 40 minutos.

- Corte y agitación:

Se realizan 20 segundos de corte (con el dispositivo diseñado) con movimientos horizontales $y$ 
verticales, seguido de tres minutos de reposo. Esta operación durante 20 minutos.

- Reposo:

Se deja reposar por cinco minutos con el objetivo de que los granos de cuajada desueren y sedimenten.

- Primera centrifugación:

Esta operación se efectúa a 1100 rpm. En el presente trabajo en esta etapa se estudian dos variantes por 15 minutos y 30 minutos, a $11^{\circ} \mathrm{C}$. Su fin es lograr una compactación ligera de la cuajada que permita disminuir el ritmo de desuerado de los granos antes de ser sometidos a la cocción.

- Desuerado:

Una vez terminada la centrifugación, el suero es eliminado por decantación de los tubos de ensayo.

\section{- Cocción:}

Se realiza en baño termostatado a $37^{\circ} \mathrm{C}$ hasta que el suero alcance un valor de $\mathrm{pH}$ igual a seis (aproximadamente $11 / 2 \mathrm{~h}$ después), volteando los tubos cada 30 minutos.
- Segunda centrifugación:

Se centrifuga nuevamente la cuajada a $1100 \mathrm{rpm}$ por 30 minutos o 60 minutos (tiempos en estudio) para finalmente ajustar la humedad del queso.

- Desuerado:

El suero sobrenadante se decanta una vez concluida la centrifugación.

- Salado:

Para proceder con el salado se extraen los miniquesos de los tubos de ensayo y se sumergen en salmuera durante cinco minutos. La salmuera se prepara al $20 \%$ con agua previamente hervida. La misma se filtra para eliminar partículas de suciedad que puedan transmitirse al miniqueso. Su temperatura es de 11$12{ }^{\circ} \mathrm{C}$ y el $\mathrm{pH}$ de 5,8 .

- Limpieza y secado:

Con el fin de eliminar la humedad excedente resultado del salado y cualquier suciedad de la superficie del miniqueso, el mismo se seca mediante el uso de un paño de gaza previamente higienizado. 
- Conservación:

La conservación de los miniquesos frescos se realiza de $2-8 \stackrel{\circ}{\circ}$.

\section{Evaluación de la calidad químico- física y sensorial y de los miniquesos}

Como resultado de realizar el proceso tecnológico bajo el estudio de los dos tiempos de centrifugación se producen 2 variantes de miniquesos cuya calidad químicofísica se compara entre ellos y con la del queso producido industrialmente.
La Tabla 1 muestra los resultados promedios de las determinaciones químicas y físicas realizadas como parte de la evaluación de la calidad. Los valores se encuentran dentro de los rangos normados por NC 78-28: 1986 para el pH y contenido de humedad, en cambio, los miniquesos sometidos al segundo tratamiento incumplen lo normado para la GES en este tipo de queso que debe ser de un $35 \%$ como mínimo. La materia grasa se encuentra dentro del rango de 18 a $29 \%$, coincidiendo con lo reportado (Trancoso-Reyes et al., 2014).

Tabla 1. Medias de las determinaciones realizadas a los miniquesos y muestras del queso industrial.

\begin{tabular}{|c|c|c|c|c|}
\hline Variantes & $\begin{array}{c}\text { Humedad }(\% \\
\mathbf{m} / \mathbf{m})\end{array}$ & pH & $\begin{array}{c}\text { Grasa }(\% \\
\mathbf{m} / \mathbf{m})\end{array}$ & GES \\
\hline $\begin{array}{c}\text { Tiempo de centrifugación } \\
\mathbf{1 5} \text { y } \mathbf{3 0} \text { min }\end{array}$ & $48,44(0,69)$ & $6,03(0,07)$ & $25,67(0,52)$ & $49,79(1,14)$ \\
\hline $\begin{array}{c}\text { Tiempo de centrifugación } \\
\mathbf{3 0} \text { y } \mathbf{6 0} \text { min }\end{array}$ & $31,65(1,4)$ & $5.97(0,05)$ & $22,33(0,82)$ & $32,36(1,67)$ \\
\hline $\begin{array}{c}\text { Muestras de queso } \\
\text { fresco industrial }\end{array}$ & $47,53(1,53)$ & $6,03(0,14)$ & $28,85(1,86)$ & $54,95(2,95)$ \\
\hline
\end{tabular}

Fuente: Salinas-Rojas (2021).

Los resultados del análisis estadístico correspondiente a la comparación entre las diferentes variantes se muestran en la Tabla 2. En la misma se evidencia que existen diferencias significativas entre las medias de los porcentajes de humedad de los miniquesos elaborados con diferentes tratamientos de tiempo de centrifugación. También difieren los 
resultados de los miniquesos producidos con 30 y $60 \mathrm{~min}$ de centrifugación y las muestras de queso fresco industrial.

Tabla 2. Comparación de las medias de los porcentajes de humedad, grasa y GES de las variantes en estudio.

\begin{tabular}{|l|c|c|}
\hline \multicolumn{1}{|c|}{ Variantes comparadas } & Diferencia (\%) & +/- Límites \\
\hline Humedad miniqueso T1 - Humedad miniqueso T2 & $16,7917^{*}$ & 1,59651 \\
\hline Humedad miniqueso T1 - Humedad queso industrial & 0,905 & 1,38261 \\
\hline Humedad miniqueso T2 - Humedad queso industrial & $-15,8867^{*}$ & 1,38261 \\
\hline Grasa miniquesos T1 - Grasa miniquesos T2 & $3,33^{*}$ & 1,712 \\
\hline Grasa miniquesos T1 - Grasa queso industrial & $-3,19^{*}$ & 1,483 \\
\hline Grasa miniquesos T2 - Grasa queso industrial & $-6,52^{*}$ & 1,483 \\
\hline GES miniqueso T1 - GES miniqueso T2 & $17,4217^{*}$ & 2,82612 \\
\hline GES miniquesoT1 - GES queso industrial & & 2,44749 \\
\hline GES miniqueso T2 - GES queso industrial & $-5,1675^{*}$ & 2,44749 \\
\hline
\end{tabular}

* Denota diferencias significativas para $p \leq 0,05$.

Fuente: Salinas-Rojas (2021).

Entre las principales condiciones de procesamiento que afectan el desuere se encuentran la velocidad de corte, tamaño de la cuajada, duración de la agitación, etc. (Panthi et al., 2018). En los miniquesos elaborados con un mayor tiempo de centrifugación se aumentó también la extracción de suero de la cuajada originando las diferencias obtenidas con respecto al contenido de humedad de los miniquesos sometidos a un menor tiempo y a los quesos fabricados en la industria.
Los resultados del análisis del pH muestran que no existen diferencias significativas $(p \leq 0,05)$ entre las medias de los valores de $\mathrm{pH}$ de los miniquesos elaborados con 15 y 30 min de centrifugación, 30 y 60 min y las muestras de queso industrial.

$\mathrm{El} \mathrm{pH}$ incide en las interacciones que se producen entre las proteínas de la leche, lo que afecta principalmente las propiedades texturales del queso. Constituye uno de los factores más influyentes en la desnaturalización de las proteínas y 
las posteriores interacciones de las proteínas del suero con las miscelas de caseína. A mayor cantidad de caseína intacta mayor es la dureza del queso (Bulut-Solak \& Akin, 2019).

Los resultados que se presentan en la Tabla 2 evidencian que hay diferencias significativas en el contenido de grasas de todas las medias analizadas. La mayor diferencia se encuentra entre la media de las muestras de queso industrial y la de los miniquesos elaborados con el empleo de 30 y 60 minutos de centrifugación. Las diferencias entre el contenido de grasa de los miniquesos y el de las muestras de queso industrial coinciden con lo reportado por Trancoso-Reyes et al. (2014). Esta variación puede ser causada por el menor tamaño del grano de la cuajada, obtenido del corte con el dispositivo empleado, con relación al que típicamente se forma durante la fabricación de queso industrial. Otro factor puede ser la centrifugación, la que facilita la separación de las fases y que, combinado con un pequeño tamaño de grano, favorece una mayor pérdida de grasa en el suero. Esto explicaría por qué en los miniquesos elaborados con mayor tiempo de centrifugación las pérdidas de este componente son superiores.

Independientemente de las diferencias, las medias del contenido de materia grasa analizadas se encuentran dentro del rango 18-29 $\%$, coincidiendo con lo reportado por Trancoso-Reyes et al. (2014).

Con respecto a la GES existen diferencias significativas entre los dos tratamientos empleados en el estudio y con respecto al valor del queso industrial, siendo mayor la diferencia entre estos últimos y los miniquesos elaborados con 30 y 60 minutos. La situación antes mencionada se debe a que los miniquesos sometidos a un tratamiento con mayor tiempo de centrifugación presentaron contenidos de humedad y materia grasa considerablemente inferiores al de los quesos industriales y los miniquesos con 15-30 minutos de centrifugación, reafirmando las diferencias que anteriormente se presentaron. Según la NC 78-28: 1986, el contenido mínimo permisible de GES para este tipo de queso es de un $35 \%$, por lo que tanto los miniquesos sometidos a 
tratamiento T1 como los quesos industriales cumplen con lo especificado. No sucede así con los miniquesos elaborados con mayor centrifugación, cuyos resultados se muestran por debajo.

A partir del análisis de los resultados de los indicadores químico-físicos se aprecia que los miniquesos elaborados con los tiempos de centrifugación de 15 y 30 minutos son los que tienen una calidad químico-física similar a la de los quesos fabricados industrialmente.

El resultado del análisis sensorial de los miniquesos elaborados con tiempo de centrifugación de 15 y 30 min fue el siguiente: superficie lisa, brillante, de color blanco a amarillo claro. La masa contenía cavidades con indicios de gránulos de cuajada, con una textura firme al corte. El olor fue aromático, típico de cuajada fresca, con sabor ligeramente ácido. Como resultado del PAES se obtuvo una puntuación total de 20 puntos, para una evaluación de excelente y en correspondencia con los atributos organolépticos que se obtienen industrialmente en el queso Fresco Criollo.
El proceso tecnológico diseñado, con el empleo de 15 minutos para la primera centrifugación y 30 minutos para la segunda y el dispositivo de corte de la cuajada confeccionado, posibilitaron la elaboración de los miniquesos Fresco Criollo cuyas características físico-químicas y sensoriales fueron similares a la de los quesos producidos en la industria. Su uso puede facilitar la realización de investigaciones al hacer posible la producción simultánea de 12 miniquesos de 6-8 $\mathrm{g}$, los cuales pueden ser elaborados con diferentes tratamientos.

\section{Conclusiones}

El procedimiento tecnológico desarrollado posibilita la producción de miniquesos a escala de laboratorio con una calidad químicofísica y sensorial similar a la de los quesos Frescos criollos de fabricación industrial. De los tiempos de centrifugación estudiados el de 15 y 30 min de centrifugación muestra los mejores resultados. La mayor diferencia entre los diferentes tratamientos analizados consiste en el menor tamaño del grano de cuajada, característicos a la tecnología empleada. 


\section{Bibliografía}

Bachmann, H., Kruijswijk, Z., Molenaar, D., Kleerebezem, M., \& van Hylckama Vlieg, J. (2009). A high-throughput cheese manufacturing model for effective cheese starter culture screening. Journal of dairy science, 92(12), 58685882. Recuperado de: https://doi.org/10.3168/jds.20 09-2372

Bulut-Solak, B., \& Akin, N. (2019). Impact of Cooking pH Values on the Textural and Chemical Properties for Processed Cheeses with/without the Use of Traditional Village Cheese during Storage. Food Science of Animal Resources, 39(4), 541-554. Recuperado de doi: 10.5851/kosfa.2019.e34

Del Rio, B., Redruello, B., Ladero, V., Fernandez, M., Martin, M. C., \& Alvarez, M. A. (2016). Putrescine production by Lactococcus lactis subsp. cremoris CECT 8666 is reduced by $\mathrm{NaCl}$ via a decrease in bacterial growth and the repression of the genes involved in putrescine production. International journal of food microbiology, 232, 1-6. Recuperado de: https://doi.org/10.1016/j.ijfood micro.2016.05.010

Fox, P. F., Guinee, T. P., Cogan, T. M., \& McSweeney, P. L. (2017). Fundamentals of cheese science. ISBN: 978-14899-7681-9.

Giri, S. K., Tripathi, M. K., \& Kotwaliwale, N. (2018). Effect of composition and storage time on some physicochemical and rheological properties of probiotic soycheese spread. Journal of food science and technology, 55(5), 1667-1674.

Recuperado de: https://doi.org/10.1007/s1319 7-018-3078-1

Henderson, L., Cabrera-Villamizar, L., Skeens, J., Kent, D., Murphy, S., Wiedmann, M., \& Guariglia-Oropeza, V. (2019). Environmental conditions and serotype affect Listeria monocytogenes susceptibility to phage treatment in a laboratory cheese model. Journal of dairy science, 102(11), $\quad$ 9674-9688.

Recuperado de: https://doi.org/10.3168/jds.20 19-16474

Ministerio de la Industria Alimenticia. (2006). Instrucción-SCC-213-01-01-1 Evaluación Sensorial. Procedimiento Analítico General para productos de la Industria Láctea cubana. Cuba: MINAL.

Ministerio de la Industria Alimenticia. (1954). NEIAL-1609-27 Queso Blanco. Proceso tecnológico. Camagüey, Cuba: MINAL. 
Ministerio de la Industria Alimenticia. (1984). NC-78-18 Leche y sus derivados. Quesos. Determinación del contenido de materia grasa.

Ministerio de la Industria Alimenticia. (1986). NC-78-28 Quesos frescos. Especificaciones de calidad. Cuba: MINAL.

Panthi, R. R., Kelly, A. L., Hennessy, D., McAuliffe, S., Mateo, M., O'Donnell, C., . . . Sheehan, J. J. (2018). Kinetics of moisture loss during stirring of cheese curds produced from standardised milks of cows on pasture or indoor feeding systems. International Journal of Dairy Technology, 71(3), 663-672. Recuperado de: https://doi.org/10.1111/14710307.12489

Peralta, G. H., Wolf, I. V., Perotti, M. C., Bergamini, C. V., \& Hynes, E. R. (2016). Formation of volatile compounds, peptidolysis and carbohydrate fermentation by mesophilic lactobacilli and streptoccocci cultures in a cheese extract. Dairy Science \& Technology, 96(5), 603-621. https://doi.org/10.1007/s1359 4-016-0291-4

Pham, N. P., Landaud, S., Lieben, P., Bonnarme, P., \& Monnet, C. (2019). Transcription Profiling Reveals Cooperative Metabolic Interactions in a Microbial Cheese-Ripening Community Composed of
Debaryomyces hansenii, Brevibacterium aurantiacum, and Hafnia alvei. Recuperado de:

https://doi.org/10.3389/fmicb. 2019.01901

Santiago-López, L., Aguilar-Toalá, J. E., Hernández-Mendoza, A., Vallejo-Cordoba, B., Liceaga, A. M., \& González-Córdova, A. F. (2018). Invited review: Bioactive compounds produced during cheese ripening and health effects associated with aged cheese consumption. Journal of dairy science, 101(5), 3742-3757. https://doi.org/10.3168/jds.20 17-13465

Trancoso-Reyes, N., GutiérrezMéndez, N., Sepulveda, D., \& Hernández-Ochoa, L. (2014). Assessing the yield, microstructure, and texture properties of miniature Chihuahua-type cheese manufactured with a phospholipase A1 and exopolysaccharide-producing bacteria.

https://doi.org/10.3168/jds.20 13-6624

Yeluri Jonnala, B., McSweeney, P. L., Sheehan, J. J., \& Cotter, P. D. (2018). Sequencing of the cheese microbiome and its relevance to industry. Frontiers in microbiology, 9 (1020). Recuperado de: https://doi.org/10.3389/fmicb. 2018.01020 